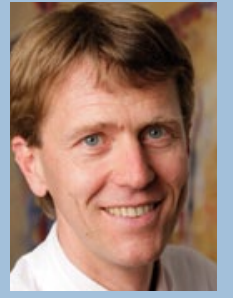

Prof. Dr. med. Heribert Schunkert München, Kardiologie

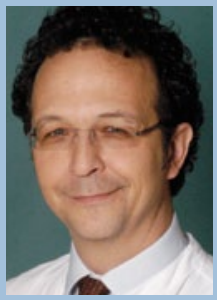

Prof. Dr. med. Thorsten Siegmund München, Diabetologie

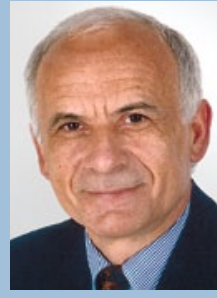

Prof. Dr. med. Alfred Wirth Bad Rothenfelde, Adipositas

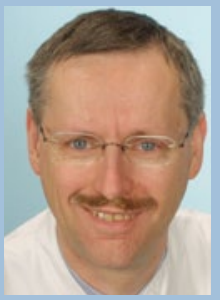

Prof. Dr. med. Walter Zidek Berlin, Hypertensiologie

\section{Nach Herzinfarkt das Thema Sex auch bei Frauen ansprechen}

\author{
Patienten, vornehmlich aber Frauen, erhalten nach einem Herzinfarkt \\ kaum Informationen und Hinweise zu der Frage, ob und wann sie wieder \\ sexuell aktiv werden können.
}

A nhand eines strukturierten Telefoninterviews wurden 17 Frauen nach akutem Herzinfarkt in einer stabilen Partnerschaft zu ihren sexuellen Aktivitäten gefragt. Ihr Sexualleben beschrieben die Frauen vor dem Infarkt eher positiv oder neutral, nach dem Infarkt indifferent oder gleichgültig. Geschlechtsverkehr nach dem Infarkt war seltener, wurde aber als inniger und befriedigender eingestuft. Die Patientinnen und ihre Partner hatten Angst, einen Reinfarkt zu provozieren. Eine Frau sagte: „Ich war sehr engagiert, aber dann doch sehr besorgt über meinen schnellen Herzschlag“. Trotzdem war vier Wochen nach dem Infarkt die Mehrzahl der Frauen wieder sexuell aktiv, nach sechs Monaten waren es mit einer Ausnahme alle.

Die überwiegende Zahl der Frauen hatte zum Thema Sex nach dem Infarkt keinerlei Hinweise von ihren Ärzten erhalten. Einige Frauen, die das Thema aktiv angesprochen hatten, waren durch die Aussagen hinsichtlich des Beginns und der Aktivität eher verunsichert („Das hängt von Ihnen ab, wie Sie sich fühlen“ oder „Wenn Sie zwei Etagen ohne Atemnot steigen können" bei einer Frau, die das auch vor dem Infarkt nicht konnte, aber sexuell aktiv war).

Abramsohn EM et al. „I'm not just a heart, I'm a whole person here": A qualitative study to im- prove sexual outcomes in women with myocardial infarction. J Am Heart Ass 2013: doi: 10.1161/ JAHA.113.000199

Kommentar: Nach den Leitlinien der amerikanischen und europäischen Fachgesellschaften sollen Ärzte ihre Patienten frühzeitig nach einem Herzinfarkt, d. h. bei Entlassung aus der stationären Behandlung hinsichtlich körperlicher und sportlicher Betätigung und Autofahren, aber auch hinsichtlich ihrer sexuellen Aktivitäten beraten.

Studien haben gezeigt, dass Geschlechtsverkehr nach einem Herzinfarkt in kardiologischer Hinsicht relativ sicher ist und - so die europäische kardiologische Gesellschaft - früh nach dem Infarkt und angepasst an die körperliche Leistungsfähigkeit wieder aufgenommen werden kann. Laut der American Heart Association können stabile Patienten nach zehn Tagen wieder sexuell aktiv sein.

Auch im mittleren und höheren Lebensalter ist Sex für viele Patien-

Wie riskant ist Sex nach dem Infarkt? Das interessiert Mann und Frau gleichermaßen. ten ein wichtiger Bestandteil des Lebens und des Wohlbefindens, der aber bei Frauen nur selten und dann häufig nur oberflächlich und unverbindlich nach einem Herzinfarkt thematisiert wird. Eine Studienteilnehmerin monierte: "Ich bin nicht nur ein Herz, sondern ein ganzer Mensch."

Eine individuelle Beratung zu sexuellen Aktivitäten unter Berücksichtigung kardialer und psychologischer Kriterien sollte bei der Klinikentlassung nach einem Herzinfarkt regelmäßig angeboten werden.

\section{Prof. Dr. med. Heinrich Holzgreve,}

Kardiologische Praxis, München

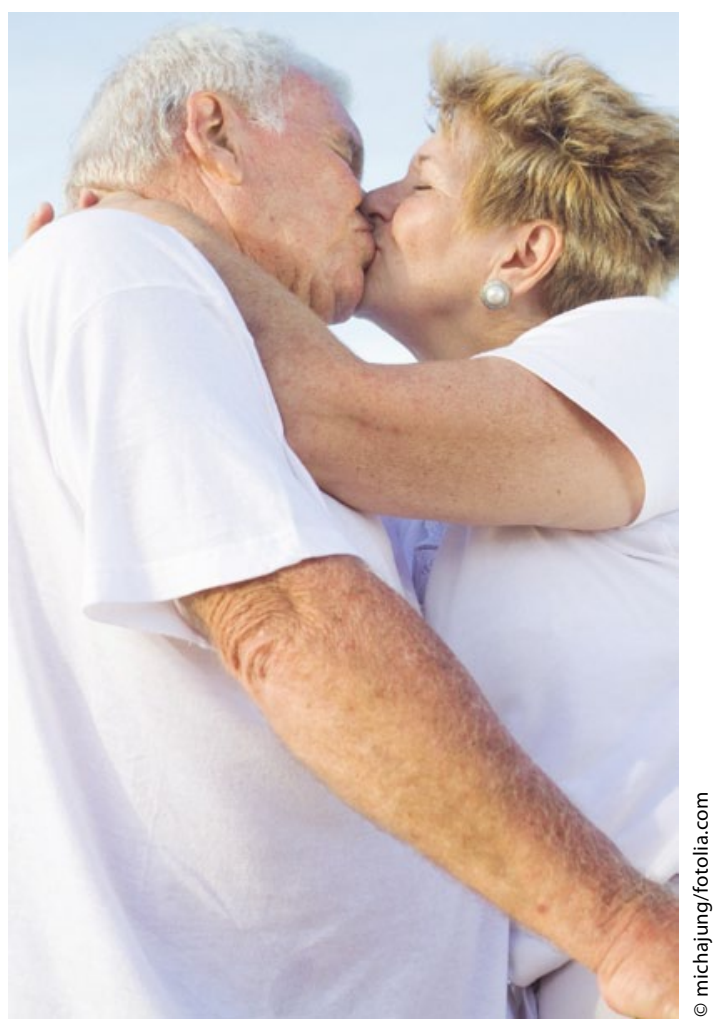

